
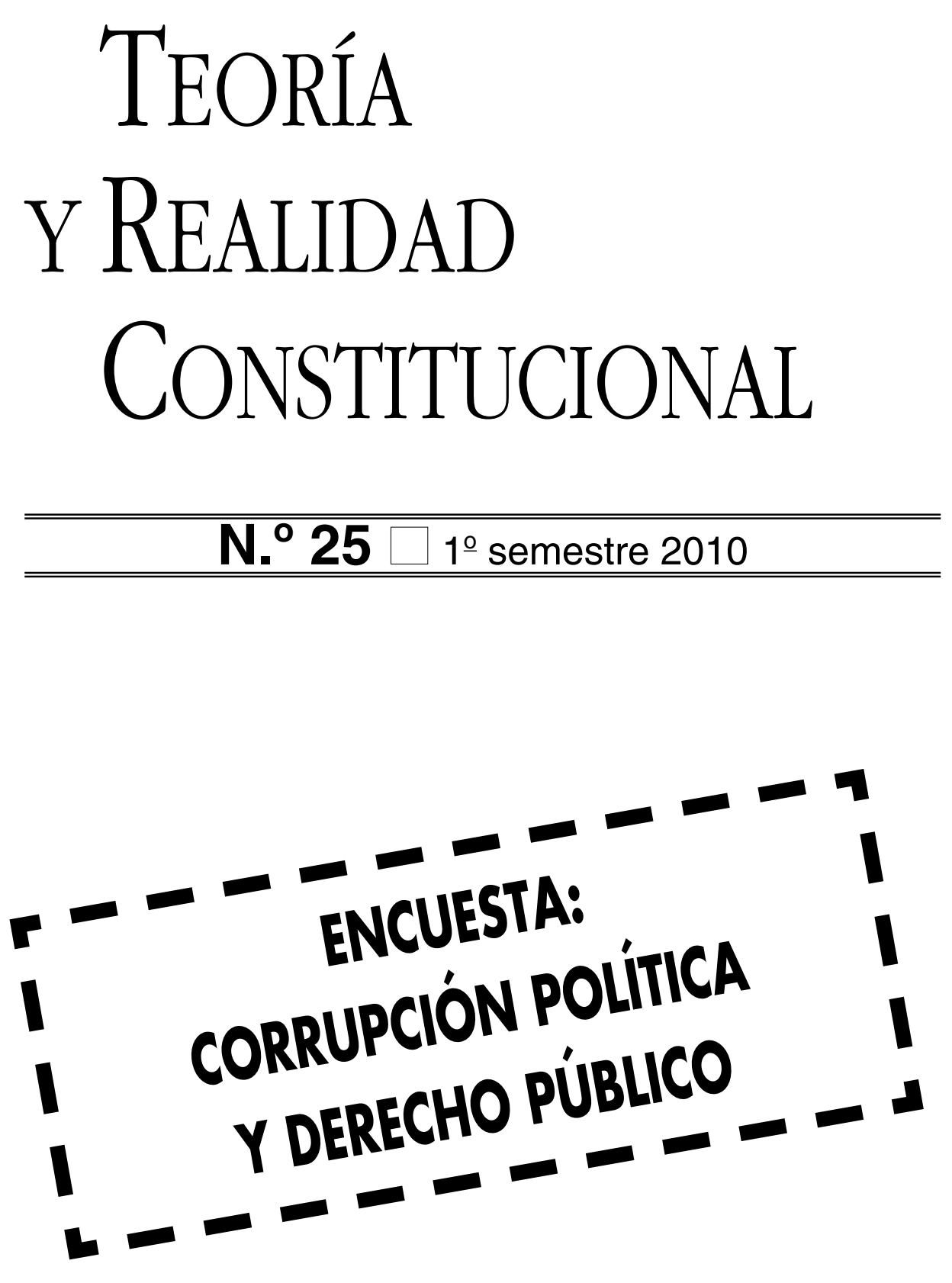


\title{
¿TODAVÍA MÁS DERECHOS? ¿DE QUÉ DERECHOS HABLAMOS?
}

\author{
SANTIAGO SÁNCHEZ GÓNZALEZ \\ Profesor Titular de Derecho Constitucional \\ Universidad Nacional de Educación a Distancia
}

\author{
SUMARIO \\ I. El menoscabo de la lengua. \\ II. Los cambios económicos y el Derecho \\ Constitucional. \\ III. La multiplicación de los derechos. \\ IV. Una breve mirada retrospectiva. \\ V. ¿De qué derechos hablamos? \\ VI. Conclusiones.
}

\section{EL MENOSCABO DE LA LENGUA}

En los últimos treinta años, el incremento y la difusión de los instrumentos para comunicarnos han sido extraordinarios. Es cierto que sobreviven todavía el correo ordinario, el telégrafo y el teléfono doméstico; también la radio tradicional y el periódico impreso Pero, desde que se introdujo el telex en algunas empresas, hasta Internet y los más recientes aparatos integradores de distintos elementos emisores y receptores, la revolución que hemos presenciado en el universo de los medios de comunicación no tiene precedentes. Ello no obstante, desde que gozamos de esa rica y abundante infraestructura para comunicarnos con nuestros semejantes, nuestra competencia lingüística, nuestra capacidad de expresión y comprensión, han disminuido ostensiblemente. Viene, pues, a darse la paradoja de que, como señaló Karl Kraus, "vivimos en una época en la que la máquinas se hacen cada vez más complejas y los cerebros cada vez más primitivos."¿Por qué?

Las razones son varias. En España, una de ellas, y determinante, es la política educativa inaugurada en el año 1970 con la aprobación de la denominada Ley Villar o Ley General de Educación, que ha continuado en las déca- 
das sucesivas ${ }^{1}$, hasta llegar a la situación actual, en la que el aprendizaje de la lengua no traspasa el umbral de la comunicación primaria. A ello ha venido contribuyendo, en buena medida, la pésima utilización de la lengua por muchos periodistas y por la clase política, comprensiva tanto de los responsables directos de la gobernanza de España, como de todo el aparato administrativo y judicial que sostiene el sistema. Unos y otros, 'comunicadores sociales' y profesionales de la política, movidos respectivamente por el deseo de lograr mayores audiencias y de sintonizar mejor con el electorado, no han tenido escrúpulos en manipular la lengua y en degradar el idioma. Ni que decir tiene que un pueblo analfabeto funcional es fácilmente dirigible y, de ahí que las oligarquías gobernantes nunca hayan pretendido generalizar la cultura ni, menos aún, estimular el pensamiento crítico. ${ }^{2}$

La incuria lingüística, que se observa en la escritura y en la conversación cotidianas, ha tenido consecuencias catastróficas. Ha supuesto, como es obvio, la merma notable de su función primera y primordial: la capacidad de expresión y de comprensión. Al mismo tiempo, la pérdida de la capacidad expresiva ha conllevado la pérdida de la capacidad discursiva, es decir, de la facultad de formular pensamientos de forma clara y ordenada, de elaborar e interpretar textos de cierta complejidad, y de realizar satisfactoriamente las operaciones intelectuales de abstracción, de análisis y de síntesis. Y no podía ocurrir de otra manera. Porque, como es sabido, existe una estrecha interdependencia entre el lenguaje y el pensamiento, porque el lenguaje es el tejido del pensamiento, y no es posible idear bien cuando se conoce mal el idioma $\mathrm{o}$, dicho de otro modo, conocer bien el idioma es requisito indispensable para pensar bien. ${ }^{3} \mathrm{Y}$ así, la regresión lingüística se ha traducido en un empobrecimiento cultural y humano, en una época en la que, como se ha apuntado, existe una abrumadora riqueza de medios y aparatos para expresarse y comunicarse.

La incesante degradación de la lengua ha afectado inevitablemente a los lenguajes especializados, es decir, a aquellos instrumentos que sirven para transmitir y adquirir conocimientos propios de las ciencias, las artes y las

1 Merced a normas como La Ley de Reforma Universitaria (1983), la Ley Orgánica General del Sistema Educativo (1986), La Ley Orgánica de Calidad de la Educación (2002) y la Ley Orgánica de Educación (2006). Véase, por todos, la obra de A. DELIBES LINIERS La gran estafa. El secuestro del sentido común en la educación, Grupo Unison Ediciones, Madrid, 2006.

2 "Dejen los políticos de decir qué «sabio, maduro y prudente es el pueblo español [...] que es ignaro y obtuso. [...] Digámoslo a las claras: la cultura en general, los idiomas y las humanidades son la asignatura pendiente de la democracia española, cojitranca por ello, con las debidas excepciones." L.A. DE VILLENA “¿Tendrá lectores Montaigne?”, El Mundo, 5.12.2007.

3 Aunque el pensamiento no es reducible al lenguaje, las palabras son indispensables tanto para comunicarse como para pensar; lo cual es tanto como decir que no se puede pensar sin lenguaje; el lenguaje no es pensamiento, pero el uno no existe sin el otro. G. SARTORI, La Politica. Logica e Metodo in Scienze Sociali, SugarCo Edizioni, Milano 1979, pág. 24. "Un pueblo inculto no sabe pensar (puesto que se piensa con el lenguaje) y, por tanto, ni es verdaderamente libre, ni tiene acceso real a las virtudes de la democracia, que son virtudes de libertad[...]". L.A. DE VILLENA, cit. en la nota anterior. 
letras, como la arquitectura, la medicina, la física, el derecho, o la filosofía. Ámbitos en los que resulta indispensable precisar y definir el significado de las palabras que se usan, al objeto de formular con exactitud las ideas y las nociones de los conocimientos que se transmiten. En el mundo del Derecho, en concreto, el fenómeno descrito ha revestido una especial gravedad dada su naturaleza esencialmente social —ubi societas ibi ius-. Porque, menester es recordarlo, el Derecho es antes que nada un lenguaje, un lenguaje formal que prescribe y ordena el comportamiento en las relaciones humanas; con la particularidad de que el Derecho tiene un alcance universal, puesto que se dirige a toda la población de un contexto geopolítico determinado.

Estamos hablando del Derecho positivo, es decir, del conjunto de normas que regulan la vida en comunidad, para posibilitar la existencia en paz y en libertad. En ese conjunto de normas, destaca por su importancia y posición jerárquica una en particular, a la que se califica de fundamental, o de norma normarum, que se conoce con el nombre de Constitución. La Constitución es el fundamento de todas las leyes de una comunidad y su ley suprema, que rige la vida social, mediante el establecimiento de unas pautas generales de conducta que deben obedecer gobernantes y gobernados. Esa aplicabilidad general exige que, de ser posible, destaque la claridad y la brevedad en su formulación, para que todos puedan comprender el significado de los mandatos legales, a fin de cumplirlos y de acomodar la vida en sociedad a un comportamiento acorde con aquellos. La Constitución es la plasmación en términos jurídicos de la organización político-social, que se adopta para garantizar prioritariamente la convivencia en paz, de una paz asentada en la justicia, y en la libertad.

Pues bien, también las constituciones, y en particular la Constitución española formalmente vigente, se han visto contagiadas por la degradación de la lengua como instrumento básico de comunicación. Y decimos esto, porque si siempre se ha exigido de los redactores de las leyes un exquisito cuidado en su elaboración ${ }^{4}$, parece que, con mayor razón si cabe, habría que haberlo demandado de la confección de la norma que ocupa la cima de toda la pirámide legal. Por desgracia, entre los 'padres fundadores' del nuevo orden jurídico-político que se inauguró en 1978, primaron otras preocupaciones, o se otorgó prioridad a otros intereses distintos del de la redacción del texto constitucional. Ello explica que, por ejemplo, se ignorasen viejos principios jurídicos como los que dicen que la claridad no necesita de interpretación -in claris non fit interpretatio-, y que las mejores leyes son las que dejan poco margen a la libre voluntad de los jueces —leges illae optimae quae arbitrio iu-

4 "A toda legislación se le pueden y deben exigir dos requisitos: que sea perfecta, formal y materialmente, es decir, que formule sus preceptos de una manera clara, inequívoca y exhaustiva; y que ordene las instituciones civiles de una manera sabia y conveniente de completa conformidad con las necesidades de sus súbditos". Así se expresaba en 1814, A. F. JUSTUS THIBAUT en su polémica con F. K. VON SAVIGNY a propósito de la codificación del Derecho. En THIBAUT y SAVIGNY. La Codificación, Aguilar, Madrid, 1970, pág.11. 
dicis pauca relinquunt-; como si el nuevo sujeto de la soberanía no sintiese la necesidad de dotar de certeza y seguridad jurídicas a su vida y a sus relaciones. Importa señalar a este respecto que la aprobación mayoritaria y entusiasta de una ley de la importancia de la Constitución, no es garantía de orden, claridad, precisión y sistema. En el caso español, contábamos con una experiencia constitucional secular, y disponíamos de tiempo y medios para realizar un buen trabajo. Podíamos haber evitado las ambigüedades, los conceptos jurídicos indeterminados, la falta de sistema y, en todo caso, las contradicciones. A pesar de ello, se reprodujeron esos defectos, que se atribuyeron a la pluralidad de fuerzas concurrentes en la redacción y al necesario consenso ideológico; y, luego, justificaron la yuxtaposición de ideologías y preceptos mediante la calificación del texto final de abierto, flexible y plural.

Plural fue, desde luego, el lenguaje escogido para referirse a los derechos y libertades, aunque tal pluralidad no fuera digna de alabanza. En efecto, nuestros 'padres' constituyentes, lejos de establecer una selección breve, rigurosa y sistemática de derechos individuales, y de una cláusula del estilo de la incluida en la enmienda novena de la Constitución norteamericana, en el sentido de considerar meramente enunciativa la relación de derechos constitucionalizada, carecieron del sentido de la medida, y del rigor terminológico. Siguieron, así, la corriente internacional predominante, que no cesa de elaborar enjundiosas declaraciones de derechos, sin preocuparse por su denominación, contenido, precisión o garantía.

La poderosa presión 'progresista' condujo, además, a aceptar que se introdujesen expresamente algunos valores en el articulado - la libertad, la igualdad, la justicia y el pluralismo político-, sin pensar con detenimiento en las consecuencias de dicha axiologización para la aplicabilidad de la norma constitucional. Pues es obvio que si se afirma que los preceptos constitucionales — salvo los meramente organizativos o procedimentales - incorporan valores, la aplicación de la Constitución requerirá de un método interpretativo algo distinto del utilizado, si se considera que las normas son meras reglas, confiriendo de este modo un amplio margen discrecional al intérprete de turno. ${ }^{5}$ Porque las Constituciones que - como la española - incorporan contenidos materiales que adoptan la forma de derechos, principios, directrices y valores [...] presentan un alto grado de indeterminación, destacando [...] el tipo

5 «El Derecho por principios $-\mathrm{y}$ valores, cabe añadir - tendría necesidad de una metodología interpretativo-aplicativa no deductiva como la de la subsunción, sino de una técnica ponderativa conectada a la razonabilidad práctica y a instrumentos equitativos (G. ZAGREBELSKY). Una metodología, por lo tanto, dirigida a la ponderación o al balanceamiento de los principios y de los valores en juego, en cada ocasión transportados al caso concreto[...] El intérprete, en el fondo deberá elegir entre la estricta legalidad y la justicia sustancial, adoptando la solución menos traumática [...] haciendo prevalecer uno u otro valor continentemente relevante.[...] Es claro que el intérprete privilegiado [...]será el juez de las leyes [...] que se transforma en legislador concurrente." S. POZZOLO, "Un Constitucionalismo ambigüo", Neoconstitucionalismo, Ed. Trotta, Madrid, 2003, pág. 193. 
de vaguedad que ofrecen los conceptos esencialmente controvertidos (p.ej., la dignidad, la justicia, la autonomía) que expresan un contenido con una fuerte carga valorativa difícil de precisar. ${ }^{6}$ A lo que habría que añadir la posibilidad cierta de que se susciten conflictos entre los valores, y entre los valores y algunos de los principios, dada la ausencia de un orden jerárquico entre ellos. Esa indeterminación, defendible por los que confían, a la postre, en el activismo político del juez constitucional, consagra en realidad un sistema de inseguridad jurídica generalizado, en flagrante contradicción con el que la solemne proclamación del Estado español como Estado de Derecho pretendió establecer.

\section{LOS CAMBIOS ECONÓMICOS Y EL DERECHO CONSTITUCIONAL}

Si el menoscabo de la lengua, y concretamente del lenguaje jurídico, es un fenómeno que reviste especial gravedad en España, hemos asistido, a otro de enorme alcance, que está afectando seriamente no solo a la economía, sino también al conjunto del Derecho español y al Derecho constitucional español, especialmente en lo que hace la administración de justicia y al entendimiento de los derechos fundamentales. Nos referimos a la formación de un sistema transnacional de poder, no localizable en un ámbito político territorial concreto, que se ha denominado globalización. Consiste, sobre todo, en el alumbramiento y desarrollo de un mercado mundial de las finanzas, servicios y mercancías - facilitado por la revolución tecnológica en el campo de la comunicación-, y en la aparición de sujetos económicos adaptados a las nuevas circunstancias, como las grandes empresas multinacionales, que actúan en el seno y, si es necesario sin el consentimiento, de los diferentes Estados y de las distintas organizaciones políticas internacionales.

Las manifestaciones de esa globalización son múltiples, y no guardan relación con la transferencia de competencias económicas a órganos supranacionales. Entre ellas están: $1{ }^{a}$ La dejación por los gobiernos de las funciones públicas esenciales de preservación de la paz y el orden. En relación con el exterior, la supresión del servicio militar obligatorio para los nacionales del país de que se trate y la formación de ejércitos nacionales nutridos en su mayoría de mercenarios y de miembros de las clases más pobres de la sociedades respectivas, resulta ilustrativo. En el interior, la adjudicación creciente de la labor de seguridad de las vidas, haciendas y libertades ciudadanas a compañías de seguridad privadas; $2{ }^{a}$ La asunción por empresas privadas de la prestación se servicios esenciales para la comunidad, como el agua, el gas y la electricidad; y del control de tráfico y de las comunicaciones. $3 .^{a}$ En el horizonte se dibujan, por añadidura, los perfiles de un sistema privado de asis-

6 S. SASTRE ARIZA, "La Ciencia Jurídica ante el Neoconstitucionalismo", Neoconstitucionalismo, op. cit., pág. 241. 
tencia sanitaria y seguridad social y de una gestión del sistema penitenciario igualmente privada. $4 .{ }^{a}$ La formación de una nueva geopolítica, "entre cuyos actores se incluyen los mercados globales de capital, las empresas legales transnacionales, y las nuevas formas reguladoras del negocio a escala global, como el arbitraje comercial internacional y la actividad económica electrónica." ${ }^{7}$. Estamos, por lo tanto, contemplando una intensa y progresiva disminución de poder del Estado y un desmantelamiento del Estado Social que se compensa, como si de un juego de suma cero se tratase, con un incremento proporcional del poder de las compañías anónimas privadas. Frente a ellas, no disponemos de un plan de actuación racional y coordinado, ni hemos creado los instrumentos de protección adecuados.

Ante ese panorama, el aparato intelectual del que tradicionalmente disponíamos para conceptualizar y ordenar el universo político-social, ha perdido buena parte de su utilidad, porque no refleja el estado de cosas existente. A lo largo de la Historia, nos hemos servido de diversos modelos capaces de proporcionar una imagen aproximada del contexto sociopolítico en el que vivimos. Al comienzo de la Edad Moderna, es decir a partir de la Revolución Francesa, pergeñamos un esquema que partía de la separación Estado político/Sociedad civil en el marco de la nación soberana y en buena medida autárquica; en él, la Constitución se concebía como un mecanismo de control del poder político del Estado. La Constitución, con una parte dogmática en la que se recogían algunos derechos, se limitaba a regular la estructura y la organización de gobierno y no contenía normas relativas a la sociedad civil, en cuyo ámbito regían la libertad y la autonomía individuales, capaces por si mismas de establecer cierta cohesión y orden en el seno de una sociedad gobernada por el mercado, que marchaba por si misma ${ }^{8}$. La fórmula política acuñada para tal formación político social fue la de Estado de Derecho.

Ese modelo fue objeto del aggiornamento que supuso el establecimiento del denominado Estado social, que franqueó la frontera del ámbito social, para intervenirlo y re-estructurarlo, para corregir sus injusticias y suplir sus carencias. En ese marco, las ideas directrices fueron otras: la interacción Estado/Sociedad y la consecuente difuminación de los límites entre ambos, la pérdida de la plenitud de la autonomía y la independencia de las unidades estatales de poder, la concepción de la Constitución no ya como puro sistema de gobierno, sino como ordenamiento con pretensiones de organizar la totalidad de la vida de la comunidad, en el que los derechos económicos y sociales y la búsqueda de la igualdad ocupan una atención preferente, el predominio de los grupos y las organizaciones y el abandono de la creencia prioritaria en la autodeterminación y el individualismo. ${ }^{9}$

7 S. SASSEN, Losing Control? Sovereignty in an Age of Globalization, Columbia University Press, New Cork, 1996, págs. 1, 5 y 6.

8 Recuérdese el aforismo de los fisiócratas que rezaba "laissez faire laissez passer, le monde va de lui mêmen.

9 Véase al respecto la obra de M. GARCÍA-PELAYO, Las transformaciones del Estado contemporáneo, Alianza Editorial, Madrid, 1977. 
Ese proceso de transformación de lo político continúa en el momento actual como consecuencia del aumento de la interdependencia, movido por las nuevas estrategias de producción y distribución, posibilitadas por una red global de comunicaciones y de agentes económicos internacionales. Estos, en muchos casos, disponen de un poder que traspasa las fronteras naciones y no están sometidos a la soberanía de un Estado concreto. Las nuevas estructuras políticas más amplias, en fase de construcción, tropiezan con el conservadurismo de los viejos Estados y con la oposición de los nacionalismos reaccionarios pequeño-burgueses ${ }^{10}$, y no están todavía en condiciones de afrontar el reto que supone esa nueva dimensión de la economía. En cuanto al neoconstitucionalismo, la respuesta ofrecida se ha materializado en tres medidas: a) la atribución de carácter normativo a la Constitución, sometiendo a su aplicabilidad a ámbitos excluidos siempre de su órbita, es decir, a las relaciones reguladas por el derecho privado; b) la ampliación del concepto y el número de los derechos constitucionales; c) la formulación de los derechos como principios o encarnación de valores. Pero, si mediante la primera medida se ha desembocado en la constitucionalización de todo el ordenamiento jurídico - lo que permite hablar de una tentativa de totalitarismo constitucional, con la segunda y la tercera, se ha contribuido a la desnaturalización y vaciamiento de la estructura de los derechos, tal y como eran tradicionalmente entendidos.

\section{LA MULTIPLICACIÓN DE LOS DERECHOS}

La convergencia de los dos fenómenos descritos anteriormente ha alterado profundamente el universo de los tradicionales derechos individuales, y ha servido de caldo de cultivo a una multiplicación y difusión de los denominados derechos fundamentales más allá de lo imaginable. Ya hemos visto que a las libertades individuales, se unieron pronto los derechos políticos, y a éstos, desde la posguerra, los económico-sociales. Luego, se comenzó a hablar de las generaciones de derechos, como si pudieran reproducirse de manera interminable. Más tarde el elenco se amplió: desde los derechos civiles, políticos, económicos y sociales, hasta los culturales, ecológicos y sexuales. En la actualidad se habla sin pudor ni reserva alguna de los derechos individuales y colectivos, de los derechos de grupos y de las corporaciones, o de los derechos de los pueblos. Y, también, de derechos morales, derechos de solidaridad, derechos de las personas jurídicas, derechos de los niños, e inclusive, de derechos de los animales. La propagación de esta nueva ideología de los derechos humanos, que se predica urbi et orbe, — dicen que- es señal inequívoca del progreso de la humanidad. En cuanto a los documentos legales en los que se afirman, relacionan o reconocen esos derechos y otros, también han proliferado: empezando por las constituciones de casi todos los países, si-

10 Como los nacionalismos catalán y vasco. 
guiendo por las convenciones y pactos internacionales y los acuerdos continentales, hasta las declaraciones universales.

Habría, quizás, que preguntarse por los posibles efectos que, la generalización del reconocimiento de esos derechos, puede provocar en millones de individuos, por las enormes expectativas creadas. Habría, quizás, que preguntarse si existen las mínimas condiciones objetivas para la construcción de un sistema de garantías capaz de hacer frente a las lógicas reivindicaciones que derivarán de aquel reconocimiento. Pero, con todo, como estudiosos del Derecho Constitucional, lo que más nos preocupa son las consecuencias que esa utilización y positivación masivas, pueden tener sobre la idea misma de derecho fundamental, sobre su validez y vigencia, sobre su contenido y eficacia; en breve, sobre la estructura de los derechos fundamentales, tal y como los conocíamos. ¿Debemos sumarnos silenciosos a esa poderosa corriente expansiva, abocada al vacío conceptual, por la dilatación y el desbordamiento de la noción primigenia? o ¿̇deberíamos abstenernos de contribuir a la demagogia imperante en este ámbito y detenernos, en su lugar, a recordar el origen, la definición y la decantación de los derechos fundamentales y limitaciones inherentes a su propia naturaleza. Más apropiado nos parece lo segundo.

En este sentido, hay comenzar diciendo que "hablar de "derechos" sólo tiene un significado comprensible cuando se hace en el marco de lenguajes normativos ${ }^{11}$ o deontológicos, es decir, en el marco de la moral, de la ética y, sobre todo, del Derecho. Ahora bien, nos parece que la moral y la ética, en cuanto disciplinas propias del fuero interno de las personas, que giran en torno a la bondad o la maldad de nuestras acciones, actúan o se predican en una dimensión distinta. De ahí que no podamos compartir esa opinión tan en boga que ve en lo que denominan derechos humanos "un asunto moral" $\mathrm{O}$, con más exactitud, un conjunto de exigencias éticas especialmente importantes que deberían ser protegidas eficazmente a través del aparato jurídico; ${ }^{12} \mathrm{O}$ como "conjunto de facultades e instituciones que, en cada momento histórico, concretan las exigencias de la dignidad, la libertad y la igualdad humanas, las cuales deben ser reconocidas positivamente por los ordenamientos jurídicos a nivel nacional e internacional..13 Cuáles sean esas exigencias y cuántas es una incógnita difícil de despejar; pero no lo es menos, imaginar hasta dónde pueden llegar las demandas derivadas de una dignidad o una libertad subjetivamente entendidas. Ciertamente ese tipo de definiciones es muy propio de los filósofos del Derecho y ha logrado un considerable grado de aceptación,

11 F. LAPORTA, "Sobre el concepto de derechos humanos", Doxa. Cuadernos de Filosofía del Derecho, pág. 24, Alicante, 1987.

12 A. RUIZ MIGUEL, "Los derechos humanos como derechos morales", Anuario de derechos bumanos, 6,1990, pág.152. En el mismo sentido cfr. G. ESCOBAR, Introducción a la teoría jurídica de los derechos humanos, Trama Editorial, Madrid, 2005, págs. 16 y ss.

13 A. E. PÉREZ LUÑO, Derechos Humanos, Estado y Constitución, Tecnos, Madrid, 1999, pág. 48 . 
pero no nos suministran la ayuda que necesitamos para concretar la significación última y el alcance de esos derechos. Para ello, creemos hay que traspasar el umbral de la filosofía, y buscar un significado técnico, preciso y definible en la historia de los derechos.

\section{UNA BREVE MIRADA RETROSPECTIVA}

Desde el punto de vista histórico, con el vocablo "derecho", o con la expresión "tener derecho a", dentro del sintagma "derechos humanos" O "derechos fundamentales", se han venido incluyendo, desde fines del siglo XVIII hasta el presente, diversas situaciones. Si nos remontamos a la Europa de las revoluciones liberales, los primeros "derechos" públicamente reconocidos lo fueron bajo la forma de libertades. En efecto, los primeros mecanismos que se arbitran para proteger a los individuos frente a la arbitrariedad y el abuso del poder, como por ejemplo el habeas corpus, sirven para preservar márgenes de libertad de las personas. Son las libertades mal llamadas negativas, que delimitan el ámbito de actuación del poder público que encarna el Estado, cuya única competencia al respecto consiste en abstenerse de intervenir. Son zonas que establecen la frontera entre el uso y el abuso del poder. Son, además, libertades políticas porque se reivindican en el marco de las relaciones del poder político y los gobernados o ciudadanos; y son muy pocas: la libertad de conciencia, pensamiento, y religión, la propiedad, la libertad personal, la seguridad, la libertad de circulación, la libertad de expresión y la libertad de reunión.

El status negativo de esos ámbitos de acción del ciudadano se explica, como puso de relieve la doctrina, por dos razones. En principio, porque se consideraba que "la libertad es algo natural que los hombres no han adquirido, sino que poseen por su propia condición humana; de ahí que el Estado no tuviera necesidad de proporcionársela: bastaba con que se abstuviera de destruirla, porque el hombre ha nacido libre; el Estado no tiene que liberarlo." ${ }^{14} \mathrm{Y}$, en segundo lugar, porque "las declaraciones de derechos revolucionarias se aprobaron como reacción contra los regímenes autoritarios, en los que precisamente la amenaza contra las libertades procedía de la acción - a menudo intempestiva - del Estado". ${ }^{15}$ "Se trataba — en suma- de definir con la mayor claridad posible los límites del poder, de la acción y de la competencia del Estado, y la correspondiente esfera de independencia del individuo, de modo que quedara asegurado el más completo y libre desarrollo de la personalidad individual,. ${ }^{16}$

14 J. ROBERT, Libertés publiques et droits de l’homme, pág. 41, Éditions Montchrestien, Paris, 1988.

15 Ibidem.

16 A. PASSERIN D’ENTREVES, La noción del Estado, pág.228, Euramérica S. A., Madrid, 1970. 
Todo ello no implica que fuera prescindible la actuación del Estado, pues éste había sido creado expresamente para conservar los que en las Declaraciones se llamaban los derechos naturales e imprescriptibles del hombre. Preservar la vida o la paz y garantizar la libertad y la seguridad, siempre han demandado y demandarán cierta actividad de los poderes públicos. Y así lo establecía el artículo 12 de la Declaración francesa de 26 de agosto de 1789, cuando disponía que: «la garantía de los derechos del hombre y del ciudadano exige una fuerza pública; esta fuerza — añadía - se instituye en beneficio de todos, y no para la utilidad particular de aquellos a quienes es confiada."

La inclusión de una serie de derechos en los preámbulos o en Declaraciones anexas a las Constituciones del siglo XIX, aunque supuso un avance considerable en la conquista de la libertad, distaba aún de satisfacer plenamente, porque se consideraba que los textos que los recogían carecían de valor jurídico. No les faltaba razón, porque las Constituciones eran documentos programáticos, marcos de actuación, expresivos ciertamente de una voluntad de organización del poder político, pero carentes de la fuerza de obligar. No es extraño, por lo tanto, que en épocas posteriores, los respectivos constituyentes no pusieran excesivos reparos al incremento paulatino e incesante de nuevos derechos. Estos entrañaban un aumento formal de las obligaciones del Estado en cuanto a protección, instrucción y asistencia de la ciudadanía. Pero su reconocimiento, como no podía ser de otra manera, no llevaba aparejada la creación de los instrumentos apropiados para su garantía. Fueron los derechos económico-sociales, cuya positivación partía, de un lado, de la premisa no tanto del individuo aislado, como de su situación y de sus relaciones con el grupo familiar, laboral, político, etc., y, de otro lado, de la insuficiencia del reconocimiento formal de las llamadas libertades negativas, mientras no se garantizasen a los ciudadanos las condiciones materiales para su ejercicio. Lo cual, a su vez, exigía de una actuación del Estado o de los poderes públicos que facilitara, al menos, la creación de esas condiciones objetivas. Obviamente, tal intervención política chocaba frontalmente con la concepción abstencionista del Estado, propia de la ideología liberal. La incorporación al ordenamiento constitucional de los derechos económico-sociales no se produjo, si se exceptúan las constituciones mejicana de Querétaro (1917) y alemana de Weimar $(1919)^{17}$, hasta la segunda mitad del siglo XX y, en realidad sólo en Europa Occidental.

Esa incorporación no ha dejado de plantear problemas teóricos y prácticos desde entonces. Entre ellos, podemos señalar los siguientes: $1 .^{\circ}$ Los derechos llamados negativos no son compatibles del todo con los derechos económicos y sociales, porque unos y otros no pueden protegerse plenamente sin sacrificar a algunos de ellos. $2 .^{\circ}$ Los derechos económicos y sociales no

17 Quizás debieran mencionarse como antecedentes de la legalización de algunos de los derechos económico- sociales, la Declaración de los Derechos del Hombre y del Ciudadano de la Constitución Francesa de 24 de junio de 1793, y el Preámbulo de la Constitución Francesa de 4 de noviembre de 1848. Así lo hace el Profesor J.L. CASCAJO, en la monografía La tutela constitucional de los derechos sociales, CEC, Madrid, 1988, pág. 15. 
pueden equipararse a los derechos liberales originarios, porque los intereses que aquellos protegen son heterogéneos y porque requieren para su realización una determinada estructura y organización en el ámbito económico social. $3 .^{\circ}$ Los derechos económicos y sociales no son justiciables, porque carecen de la concreción necesaria, ya que no es posible precisar de modo general sus límites ni su medida; de ahí que no se haya podido crear un entramado institucional capaz de garantizarlos, como el que creó el Estado liberal. Y es que, a la postre, bajo la etiqueta de 'derecho social' o 'derecho económico-social' se incluyen cosas tan diversas como: determinadas demandas a los poderes públicos, intereses legítimos, formas de control del ejercicio de poderes privados, necesidades primarias, meros intereses fácticos, derechos subjetivos, mandatos de actuación al legislador, directrices constitucionales a los poderes públicos y objetivos del Estado. ${ }^{18}$

En las últimas décadas, más aún recientemente, las demandas de nuevos derechos se han multiplicado. Al margen de la expansión provocada por la aplicabilidad de las normas constitucionales sobre derechos fundamentales a las relaciones entre sujetos privados — también llamada eficacia horizontal ${ }^{19}$ , el desarrollo de la personalidad, la eutanasia, el cambio de sexo, la pedofilia, el derecho a drogarse o automutilarse, el aborto, la identidad cultural, el derecho a internet, el derecho al placer y a la felicidad y el derecho a un mínimo existencial ${ }^{20}$, son algunas de las numerosas peticiones de diversos sectores de la población, que se demandan públicamente como si fueran derechos.

\section{V. ¿DE QUÉ DERECHOS HABLAMOS?}

La cuestión que tenemos que afrontar es si podemos seguir reivindicando con cierto fundamento, como verdaderos derechos, todos esas apetencias incesantes y anhelos, sin desnaturalizar el concepto mismo de derechos fundamentales, y sin vaciarlo en última instancia de contenido. Es decir, si pode-

18 K. STERN, una autoridad reconocida en Derecho Constitucional, reconoció en su día la dificultad de caracterizar a los derechos sociales como derechos fundamentales, dada su dependencia de factores como el desarrollo legislativo de los mismos y, sobre todo, la situación del erario público. Para él debería hablarse más bien de 'principios programáticos'. Véase «El sistema de los derechos fundamentales en Alemania", en Revista del Centro de Estudios Constitucionales, 1, CEPC, Madrid, 1988, págs. 261-277.

19 Vid., por todos, J.M Balbao Ubillos, La eficacia de los derechos fundamentales en las relaciones entre particulares. Análisis de la jurisprudencia del Tribunal Constitucional, CEP y P, Madrid, 1997.

20 El pasado mes de junio el parlamento regional de las Islas Baleares aprobó una denominada Ley de Servicios Sociales y reconoció el "derecho" a recibir prestaciones asistenciales. Con independencia de la duda de constitucionalidad que el reconocimiento de nuevos derechos por parte de un parlamento autonómico suscita, se han dejado para desarrollo posterior mediante decreto los problemas que esa medida plantea: quién podrá pedir esas prestaciones, qué podrá demandarse, a quién, cómo, con qué garantías y, en última instancia, que sucederá si al final no puede satisfacerse las pretensiones por falta de recursos materiales. Todo lo cual no parece importar a los políticos de turno. 
mos, en un ejercicio de mero arbitrio, ampliar el campo semántico de la expresión "derechos fundamentales" O "derechos públicos subjetivos", sin privarlos de su naturaleza originaria, sin cuestionar su operatividad y vigencia reales. Además, debemos responder a la cuestión de si es conveniente insertarlos en los textos constitucionales como tales derechos fundamentales, convirtiéndolos así en exigibles, aunque dudosamente realizables.

La idea originaria de los derechos públicos subjetivos sigue siendo una categoría central del Derecho Constitucional, en torno a la cual giran los órganos y las instituciones el edificio constitucional; de manera que si esa categoría pierde su entidad porque se dilata su concepto, se borra su perfil y desbordan sus fronteras, lo que quiebra es toda la dogmática jurídico constitucional. En efecto, si los derechos fundamentales son pretensiones subjetivas configuradas como normas vinculantes que, simultáneamente, se proyectan en el resto del ordenamiento informando la actuación de todos los poderes públicos, es obvio que su desestructuración tiene que afectar seriamente a todo el edificio constitucional. Desestructuración que se sumaría a los efectos deletéreos que sobre el Derecho Constitucional tradicional está produciendo la dirección emprendida por las corrientes más actuales, que preconiza la omnipresencia de la Constitución en toda la vida social y familiar y, por ende, en la esfera jurídico-privada. ${ }^{21}$

Si nos expresamos así, es porque ese movimiento de expansión incontrolada de los derechos, que ha acogido en su seno a todo tipo de deseos personalísimos y afanes colectivos, conduce inexorablemente a la desaparición de los mismos como conceptos determinados, es decir como representaciones intelectuales perfectamente delimitadas; y si así ocurre, no podrán servir para transmitir un significado definido, y perderán su valor como instrumento comunicativo y como actividad reivindicatoria. Serán, en suma, palabras vacías...si es que no lo son ya.

Frente a ese movimiento, que muchos califican de progresista, o revolucionario, nosotros creemos que se presta un mejor servicio a la sociedad si se defiende un concepto de derecho fundamental como derecho público subjetivo; somos partidarios de un concepto normativamente estricto de los derechos" fundamentales. "Esta opción tiene dos implicaciones: que todo derecho — si es realmente un derecho- es correlativo de uno o más deberes de otro u otros, y que tales deberes pueden ser satisfechos, pues nadie está obligado a lo que no se puede hacer.[...] Lo cual significa que si un orden legal dado declara un cierto derecho sin establecer los deberes jurídicos correspondien-

21 "La constitucionalización del ordenamiento [...] determinaría — de hecho, determina - una mutación cualitativa del Derecho por entero". G. ZAGREBELSKY El derecho dúctil. Ley, Derechos, Justicia., 1995, 2002, Ed. Trotta, Madrid, pág. 49. 'Mutación' es, a nuestro juicio, un eufemismo de 'transformación radical' para describir los efectos del imperialismo constitucional sobre el Derecho Constitucional y el Derecho en general. Pero la verdad es que las Constituciones que, como la española, establecen el carácter normativo y vinculante de todos sus preceptos para todos - gobernantes y gobernados- proporcionan la base para que se implante un verdadero totalitarismo constitucional. 
tes a su satisfacción, simplemente el derecho no existe como derecho subjetivo positivo en ese ordenamiento o, lo que es igual, es un "derecho de papel".."22 "Para hacer que los derechos sean en última instancia practicables efectivos- es preciso elaborar una "teoría de los deberes" y, por lo tanto, de verdaderas Cartas de deberes, que individualicen a los sujetos responsables de la satisfacción de los derechos. ${ }^{23} \mathrm{Y}$, finalmente, que incluyan las sanciones aplicables cuando se incumplan esos deberes.

Desde esa óptica, carecen de fundamento científico todos los argumentos empleados para justificar la inclusión en los textos constitucionales de la mayoría de los derechos a los que se ha calificado de económico-sociales y culturales, y de las posteriores 'generaciones de derechos'; a no ser que se admitiera, y así se expresara con claridad en esos mismos textos, que la naturaleza de aquellos derechos no es jurídica, sino política y que, en consecuencia, constituyen declaraciones de intención, de programas políticos o similares. Pues, de otra manera, es decir, si se decide otorgar valor normativo a un texto constitucional, no se debería en buena lógica, incluir mandato, norma o precepto, enunciado o prescripción, que no pudiera cumplirse. Si se hace, no es sólo porque se persigan fines loables, cuya sanción constitucional — se piensa- les confiere una dimensión liberadora que se materializará en un futuro, sino porque de esa forma se enmascara la realidad con el disfraz del derecho. En la medida en que así es, el derecho constitucional se convierte en un instrumento de liberación virtual, a cuyo través la existencia político-social no es percibida como la realidad que es, sino totalmente deformada.

Un procedimiento útil para demostrar la improcedencia de recurrir arbitraria o gratuitamente a la idea de derecho subjetivo, so pena de incurrir en una grave mistificación, es comprobar el grado de eficacia, o de realización respectiva de cada 'derecho', reivindicado como derecho natural o humano, o incluso, reconocido en algún documento o Constitución, y de la causa o causas de esa falta parcial o total de efectividad del 'derecho' en cuestión. Fijémonos en la mayoría de los 'derechos' económicos y sociales, y en los otros 'derechos' que se han ido incluyendo en Constituciones y Declaraciones a partir del final de la Segunda Guerra Mundial, desde el derecho al trabajo, pasando por el derecho a una vivienda digna, o a un mínimo vital para subsistir. ¿Son realmente exigibles? ¿Ante qué jurisdicción o tribunal? La transformación de cualquier relación o situación social en un derecho subjetivo no se produce automáticamente por la mera inclusión de la misma en un texto legal, y menos aún, cuando en un mero ejercicio de voluntarismo se califica como derecho lo que no es más que una "aspiración o meta". Los redactores de mu-

22 L. HIERRO, "Los derechos económico-sociales y el principio de igualdad en la teoría de los derechos de R. Alexy", Derechos sociales y ponderación, Fundación Coloquio Jurídico Europeo, Madrid, 2007, págs. 199-200.

23 A. SPADARO, "Dall'Indisponibilità (tirannia) alla Ragionevolezza (Bilanciamento) dei diritti fondamentali. Lo sboco obbligato: l'individazione di Doveri altrettanto fondamentali", Politica del Diritto, a. XXXVII, n. 1, 2006, pág. 176. 
chos de esos textos juegan "à leur insu" a ser Zanco Panco ${ }^{24}$, pero, las palabras no significan lo que uno quiere. Incluso la misma inserción de un 'derecho' en una constitución normativa no implica necesariamente su vigencia inmediata o futura. La positivación de los derechos requiere que estos se refieran a situaciones bien determinadas en cuanto a su objeto y titularidad, en cuanto a su sujeto pasivo, en cuanto a su contenido y tutela; y, en todo caso, antes de incorporar a una norma jurídica cualesquiera aspiraciones, es menester tomar en consideración las condiciones reales de existencia para comprobar que permiten su realización. Sin esos requisitos no existen realmente derechos, aunque muchos hablen de derechos naturales o legales.

Tomemos para ilustrar nuestra posición uno de los derechos sociales básicos, que fue institucionalizado hace ya algunas décadas en los países dotados de sistemas políticos democrático-constitucionales, y considerados económicamente desarrollados. Pensamos en el derecho al trabajo, que se recogió en el artículo 35 de la Constitución española de 1978 como deber y como derecho. La doctrina autorizada ya se encargó de decir que se trataba de un derecho "tremendamente modalizado por las circunstancias socio-económicas del momento y del país de que se trate. (Y que) era un derecho pleno en su formulación y variable en su contenido." ${ }^{25}$ Podría haberse añadido que, dada su exclusión del grupo de derechos protegidos con el recurso de amparo, carecía de la garantía necesaria para su protección jurídica ${ }^{26}$. Pero, en realidad, no es sólo que el derecho al trabajo se vea siempre condicionado por la situación económica del entorno en el que se produce su reconocimiento legal o constitucional. Es que el supuesto derecho al trabajo posee un contenido relativamente indeterminado y carece de la estructura jurídica precisa para reivindicarlo como tal, porque no cuenta con los medios para exigirlo y tampoco existe el sujeto pasivo a quien exigir su satisfacción.

Analicemos, en el mismo sentido, el enunciado normativo del artículo 45 de la Constitución española vigente, que dispone que «todos tienen derecho a disfrutar de un medio ambiente adecuado para el desarrollo de la persona, así como el deber de conservarlo." El Profesor Antonio-Enrique Pérez Luño decía ya hace unos lustros que "el reconocimiento de este derecho se encuadra en la segunda función - asignada a los derechos fundamentales por Rudolf Smend-, consistente en "establecer el horizonte emancipatorio a alcanzar" .. ${ }^{27}$

24 "Cuando yo uso una palabra quiere decir lo que yo quiero que diga....ni más ni menos" —insistió Zanco Panco- -.En Alicia a través del espejo, Alianza Editorial, Madrid, 1998, pág. 123.

25 J. A. SAGARDOY BENGOECHEA, "Artículo 35. Derechos Laborales", Comentarios a las leyes políticas. Constitución Española de 1978 (Dirigidos por O. Alzaga Villamil), T. IV, pág.471, EDERSA, Madrid, 1983.

26 Por una de esas extrañas paradojas que a veces acontecen en la vida, sí se otorgó la protección jurídica del recurso de amparo al derecho al trabajo remunerado y a los beneficios de la seguridad social, además del acceso a la cultura y al desarrollo integral de la personalidad, ia los condenados a penas de prisión!

27 Citando a R. SMEND, en "Artículo 45. Medio Ambiente", Comentarios a las leyes políticas. Constitución Española de 1978. (Dirigidos por O. ALZAGA VILLAMIL), Madrid, EDERSA, 1984, T.IV, pág. 242. 
Y añadía que "es obvio que tal derecho no puede concebirse más que como una aspiración o meta, cuyo logro exige importantes transformaciones culturales y socio-económicas." La cuestión es entonces ¿por qué se le otorgó el tratamiento de derecho, cuando en realidad no era susceptible en modo alguno de concebirlo racionalmente como tal? Pensemos, por un momento, en los elementos del supuesto derecho. El titular tendría que ser cada uno de los habitantes de la tierra, porque todos sufrimos, más tarde o más temprano, la contaminación del aire y de las aguas, que no conoce fronteras geográficas, ni políticas. Nuestra acción, la de cada uno, tendría que dirigirse erga omnes, es decir, contra el resto de la humanidad, sujeto pasivo de la relación jurídica que tiene el deber de respetar y conservar el medio ambiente. ¿Ante que instancia jurisdiccional? Quizás tendríamos que crear un Tribunal de la humanidad y dotarle de la competencia y de los medios para entender de esas demandas. La sentencia que recayera sería en todo caso un pronunciamiento de condena ja la humanidad!, y de imposición de un deber universal de abstención de cualquier conducta contaminante. Y si así fuera, quedaría aun por resolver el problema de la ejecución de la sentencia, y del cómo se procedería a reparar el daño causado, es decir, del cómo se restablecería el equilibrio ecológico planetario o, subsidiariamente, se remediaría el mal causado. En suma, una utopía y una ucronía, o, en otros términos, un enorme despropósito. $^{28}$

Si partimos de esa base, todos aquellos 'derechos' en los que el titular - activo y pasivo - de los mismos no esté determinado, o en los que el objeto de los mismos sea incierto, o el contenido indeterminable de manera general, o en los que su exigibilidad y aseguramiento no estén garantizados, no deberían ser considerados derechos. Se les podrá denominar de muy diversas formas: derechos debilitados, derechos de aplicación progresiva, derechos en formación, derechos expectantes, derechos de realización aplazada o derechos imperfectos; pero, en todas ellas, el adjetivo añadido nos advierte de que no se trata en rigor de derechos. Por otra parte, en todos los mal denominados derechos colectivos - al medio ambiente saludable, a la autodeterminación, a la identidad cultural, al desarrollo sostenible-, lo que realmente subyace es la idea, sin fundamento real, de que en algún tiempo pasado, un grupo indeterminado de individuos perdió, o se vio privado de algo que a la sazón no era apreciable ni cuantificable. La atribución de la responsabilidad de esa pérdida o privación recae necesariamente en los otros, terceros, sean ellos países, o empresas, o acontecimientos, como derrotas bélicas, o incluso sistemas de producción, como el capitalismo. Lo que en definitiva importa es conseguir transmitir a la opinión pública la imagen de "un colectivo" que ha sido victima de un desafuero, que debe enmendarse por aquellos terceros.

28 Este 'derecho' al medio ambiente, como los 'derechos' a una vivienda digna y adecuada, a la cultura y al tratamiento de los disminuidos psíquicos son derechos ad ostentationem y ad captandum vulgus, o sea, que su inserción en la Constitución equivale a pedir cotufas en el golfo. 
Desde esa perspectiva, carecen de importancia la improcedencia, la extemporaneidad, la inconcreción del petitum, o la falta de legitimación procesal activa y pasiva y la ausencia de instancia jurisdiccional alguna. De lo que se trata es de que se tipifique a la reivindicación en cuestión como derecho. Luego bastará con lograr su inserción en alguna proclama o declaración 'democráticos' con visos de legitimidad. Así adquirirá la apariencia del derecho.

\section{CONCLUSIONES}

La depauperación que sufre la lengua española es un hecho incontrovertible. La riqueza expresiva, la corrección gramatical y la propiedad idiomática han cedido su carácter normativo a la vulgaridad, a la negligencia y a la ignorancia. En ese marco reductor de la comunicación humana, polemizar sobre el significado de las palabras ha perdido sentido fuera de círculos muy restringidos, porque la mayoría desconoce, y una minoría sabe muy bien, que "las palabras conforman el pensamiento". En algunos casos, hemos llegado a vaciarlas del contenido informativo que poseían hasta dejarlas hueras, circunscritas a meros signos capaces de suscitar emociones en sus receptores. Es cierto que la limitación del lenguaje —que conduce inexorablemente al empequeñecimiento de nuestra humana condición-, no ha afectado con igual fuerza a aquellas áreas del conocimiento que, por formularse en lenguajes intelectualmente complejos, están sustraídas a todo el que no esté adecuadamente preparado. Pero se ha dejado sentir con especial intensidad en la esfera del discurso político relacionada con el Derecho Constitucional y, en concreto, con la política de los derechos humanos.

Como se ha expuesto, hemos asistido, en los últimos años, a la multiplicación y a la crisis del concepto de 'derechos fundamentales'. La causa principal ha sido el vaciamiento de significado de la expresión merced a la difusión de su utilización inadecuada. Últimamente se ha llegado al extremo de equipararlos con cualquier deseo individual o de grupo. ${ }^{29}$ Pero también ha contribuido poderosamente a la citada crisis la relativización del concepto, consecuencia del concurso de dos factores. El primero, el olvido del fundamento humanista de los derechos fundamentales, al reconocer la titularidad

29 No nos sorprende que en las listas de derechos reivindicados en nuestros días, no aparezcan tres verdaderamente fundamentales. El primero es el derecho a la existencia de toda persona humana en formación, es decir, desde el comienzo de su gestación; distinto del derecho a la vida — que no es en verdad un derecho_- La política de los países pretendidamente civilizados ha frustrado la posibilidad de reconocimiento de ese derecho primero, despenalizando el aborto y, luego, promoviéndolo como derecho, e incluso financiándolo con fondos del erario público. El segundo es el derecho a la resistencia, uno de los más antiguos y preteridos, que consiste en el derecho a recuperar la libertad y desobedecer al gobierno como reacción al quebrantamiento de su misión, que es preservar la vida, la libertad y la propiedad de los ciudadanos. Y el tercero, es el derecho de todos a hablar bien y a escribir bien la lengua propia, cuya conquista seguirá demorándose mientras no se extienda la enseñanza y la cultura y se llegue a comprender que el idioma es patrimonio común. 
de algunos de ellos a sociedades mercantiles, grupos innominados y colectividades más bien difusas sin asomo de personalidad. Hay que dejar constancia de que la adjudicación de personalidad jurídica a dichas entidades a efectos jurídico-procesales o económicos, no puede, en absoluto, justificar la atribución a las mismas de los derechos dimanantes del valor intrínseco de la dignidad del hombre ${ }^{30}$. El segundo, ha sido el fruto de la caracterización axiológica de la Constitución y de los derechos en ella recogidos, sin delimitación de los contenidos de los valores enunciados. De esa forma, se ha otorgado un amplio margen de discrecionalidad a sus intérpretes, en detrimento de la certeza, de la previsibilidad y de la seguridad jurídica. Tan es así, que la Constitución y la jurisprudencia constitucional han recurrido a la noción de núcleo básico o contenido esencial — sin precisar cual sea en cada caso-, para mitigar el grado de indeterminación del derecho fundamental. Lo cual no ha impedido que el juez de la constitucionalidad continúe ponderando casuísticamente los derechos fundamentales invocados. ${ }^{31}$ Pero la fijación del contenido de un derecho fundamental, es decir, del conjunto de posibilidades de actuación que se atribuyen a su titular, no puede en cada caso y circunstancia quedar al arbitrio del juzgador de turno, por muy alto tribunal que sea. La jurisprudencia de los valores es una puerta abierta a la incertidumbre y a la arbitrariedad — prohibida por la Constitución-, que la seguridad jurídica deplora.

Nos tememos que en un futuro próximo, el movimiento reproductor de nuevos 'derechos' y de su desnaturalización va a continuar progresando. Los intérpretes supremos de los respectivos ordenamientos continuarán 'descubriéndolos' en la penumbra de los derechos tradicionales - como hace el Tribunal Supremo norteamericano-, los hallarán en alguna de las facultades propias de un derecho ya existente - como el Tribunal Constitucional español-, o en una de las proyecciones del derecho al desarrollo de la personalidad — como el Tribunal constitucional alemán—. Las grandes multinacionales proseguirán su lucha en pro de que se les reconozcan derechos absolutamente ajenos a su condición de empresas capitalistas — como la intimidad o el honor- Las minorías 'de genero', étnicas, lingüísticas y de otra ín-

30 “Sólo cuando la formación y la actividad de una persona jurídica sea una manifestación del libre desarrollo de los individuos, tiene sentido atribuir a aquella derechos fundamentales"; J.M. Díaz Lema, "¿Tienen derechos fundamentales las personas jurídico-publicas?", Revista de Administración Pública, n 20, 1989, p. 100. En ese caso, tal atribución debe hacerse con carácter de única, pues, de otra manera, los individuos integrantes de esa personas jurídica gozarían del mismo derecho como tales individuos y como miembros de la persona jurídica; una duplicidad difícilmente sostenible que, quizás pretenda explicarse arguyendo que las personas jurídicas ostentan esos derechos como propios, diferenciados, aunque sean los mismos derechos que los que sus miembros ejercen a través necesariamente de esas personas jurídicas. Precisamente lo que criticamos por carecer de fundamento es que las personas jurídicas sean titulares, como propios suyos, de derechos fundamentales.

31 Los orígenes y los inconvenientes de la ponderación fueron analizados en el artículo titulado "De la imponderable ponderación y otras artes del Tribunal Constitucional", publicado en el número 12/13 de esta Revista, 2003-2004, págs. 351-382. 
dole, plantearán nuevas demandas. Y, los que sufren de transtornos de la personalidad múltiples y transtornos bipolares exigirán el derecho a un tratamiento específico de su dolencia, es decir, el derecho al desarrollo de sus múltiples personalidades. Se suscribirán nuevos compromisos entre asociaciones de Estados en medio del entusiasmo internacional, y el discurso oficial sobre derechos humanos, que diariamente ocupa el espacio público, seguirá ganando adeptos.

Llegados a este punto, nos vemos obligados a reiterar algo que ya ha sido apuntado. Cualquier aspiración o pretensión humana —ética, moral, justa—, no es en principio más que un deseo. Para que se convierta en un derecho, seguirá siendo requisito sine qua non que pueda estructurarse como una relación jurídica. Es decir, requiere el establecimiento indubitado de: a) los sujetos - de a quién se atribuye la situación de poder en que el derecho consiste, y de quién queda vinculado al deber jurídico-; b) el del objeto, o sea, el ámbito de actuación soberana que queda sometido al poder del titular, que puede ser la conducta de otra persona o un bien; c) la delimitación de su contenido, de todas las facultades reconocidas a la persona para actuar, incluyendo la posibilidad de exigir el cumplimiento del deber correlativo; y, por último, d) las garantías jurídicas imprescindibles de su exigibilidad, acudiendo a los tribunales de justicia para pedir el pronunciamiento de una decisión y la actuación de la administración ejecutora. En fin, el reconocimiento de todo derecho precisa por añadidura que se den las condiciones objetivas - la situación económico-social- que permitan su realización o satisfacción. Algo similar proponía en otros términos el Prof. Peces Barba, cuando decía que: «una pretensión moral (justicia), para ser plenamente un derecho fundamental, tiene que ser susceptible de incorporarse a las categorías técnicas del Derecho positivo, derecho subjetivo, libertad, potestad o inmunidad (validez) y ser posible en la realidad (eficacia)". Y añadía, "probablemente la escasez sea uno de los obstáculos más grandes a la eficacia de los derechos." ${ }^{32}$

TiTLE: Still more rights? Which rights are we talking about?

ABSTRACT: In a time of multiplied and improved means of communication, the every day use of the Spanish language in Spain is under a process of degradation and impoverishment. This process affects as well its scientific use in fields like law and specifically constitutional law. On the other hand, globalization and the radical changes in communication technology have caused Constitutional Law to try to adapt itself to new circumstances. One of the responses of Constitutional Law to those transformations has been to enlarge its content by the reception as supposed rights of manifold demands and wishes. But this admission has not taken into account the real economic and social conditions of existence, and has not been accompanied neither by the formal theoretical construction, nor by the creation of the appropriate system of guarantees. The whole political and legal discourse on human and fundamental rights, which has led to the elaboration

32 "Escasez y Derechos humanos", en Problemas actuales de los Derechos Fundamentales, Madrid, Universidad Carlos III-BOE, 1994, págs. 193-313. 
of many constitutions, international agreements and declarations, has not trespassed the threshold of mere rhetoric. But it has contributed to the loss of meaning and significance of the traditional notion of rights - individual and fundamental-, and to the creation of a huge sham.

RESUMEN: Se abordan en este artículo, en primer lugar, el deterioro y empobrecimiento de la lengua española, a pesar del aumento y mejora de los medios de comunicación. A renglón seguido, se apuntan las consecuencias para la comunicación en general y para disciplinas científicas como el Derecho, y el Derecho constitucional en particular. El Derecho Constitucional se ha visto, además afectado por los grandes cambios que se han producido en la esfera económicaglobalización - y en la tecnología de las comunicaciones.Una de las respuestas del Derecho constitucional ante esa revolución ha sido ampliar su contenido mediante la recepción como supuestos derechos de múltiples peticiones y deseos de toda indole. Pero la dilatación del corpus jurídico constitucional, a la que también ha contribuido la axiologización constitucional, se ha realizado ignorando las condiciones económicas y sociales reales de existencia, y no ha ido acompañada de la construcción de una dogmática apropiada, ni de un sistema de garantías adecuado. Con lo cual todo el discurso sobre derechos fundamentales y su plasmación en instrumentos como constituciones, convenios, declaraciones, etc, se ha quedado en mera retórica y ha vaciado de significado al concepto tradicional de derechos fundamentales, contribuyendo a suministrar una imagen totalmente deformada de la realidad.

KeY WorDs: Human and fundamental rights. Spanish language. Constitutional Law.

Palabras Clave: Derechos fundamentales y humanos. Lengua española. Derecho constitucional. 